COSTANTINO, Gabriel. "Reforma acusatoria y acceso a la justicia en la provincia de Buenos Aires (Argentina)".

Polít. crim. Vol. 10, No 20 (Diciembre 2015), Art. 4, pp. 528-542.

[http://www.politicacriminal.cl/Vol_10/n_20/Vol10N20A4.pdf]

\title{
Reforma acusatoria y acceso a la justicia en la provincia de Buenos Aires (Argentina)
}

\section{Accusatory reform and access to justice in the Buenos Aires Province (Argentina)}

\author{
Gabriel Costantino \\ Doctor en Ciencia Política, Escuela de Política y Gobierno de la Universidad Nacional de \\ San Martín (UNSAM) \\ Gcostant76@gmail.com
}

\section{Resumen}

El trabajo se propone analizar la reforma acusatoria en la provincia de Buenos Aires y sus consecuencias en el acceso a la justicia. La tesis central del trabajo es que pese a la retórica de la dirigencia que reformó la organización de la persecución penal, y a los cambios acontecidos a favor de un Ministerio Público independiente del Poder Ejecutivo y con más recursos y facultades investigativas, la persecución penal ha incrementado la criminalización de las infracciones que realizan los sectores más vulnerables de la población, dejando de lado ilícitos graves como la corrupción política y la violencia policial.

Palabras clave: Reforma acusatoria, Ministerio Público, acceso a la justicia.

\begin{abstract}
The purpose of this paper is to analyze the accusatory reform in the province of Buenos Aires and its impact on access to justice. The main thesis is that despite the reformers rhetoric, and changes promoting an independent Public Prosecutor with more resources and investigative powers, the reform has increased criminalization of offences committed by vulnerable sectors of the population, leaving aside the prosecution of political corruption and police violence.
\end{abstract}

Key words: Accusatory Reform, public prosecutor, access to justice.

\section{Introducción.}

A partir del retorno de la democracia a Iberoamérica, diversos actores políticos, nacionales y regionales, comenzaron a discutir públicamente cómo reformar las instituciones de gobierno para promover un sistema de persecución penal equitativo y eficaz ${ }^{1}$. Con el paso de los años, se fue articulando un movimiento reformista iberoamericano que, bajo el

\footnotetext{
${ }^{1}$ Cfr. RICO, José María, Justicia penal y transición democrática en América Latina, México: Siglo XXI Editores, 2007; MENDEZ, Juan, O`DONNELL, Guillermo y PINHEIRO, Paulo, (Comps.), La (in)efectividad de la ley y la exclusión en América Latina, Buenos Aires: Paidós, 2002; LANGER, Máximo, "Revolución en el proceso penal latinoamericano: difusión de ideas legales”, Comparative Law, vol. 55 (2007), p. 617.
} 
COSTANTINO, Gabriel. "Reforma acusatoria y acceso a la justicia en la provincia de Buenos Aires (Argentina)".

slogan de transformar el sistema judicial inquisitorio por uno de tipo acusatorio, logró promover grandes transformaciones de las burocracias que gestionan la investigación criminal en la mayoría de los países de la región. Los objetivos principales de dicho movimiento reformista consistían en: i) instaurar un sistema penal que diferenciase claramente la función de acusar, de defender y de juzgar, y que profundizara el carácter oral y público del proceso de enjuiciamiento penal; ii) solucionar el colapso del sistema judicial de la mayoría de los países de la región, producto del congestionamiento de causas, muchas veces irrelevantes o mal elaboradas, implementando una investigación criminal más eficaz en la identificación y penalización de los delitos socialmente relevantes ${ }^{2}$.

Sin dudas, uno de los puntos clave de esta revolución legal iberoamericana ${ }^{3}$ residía en la transformación del rol y de las capacidades del Ministerio Público. Para la perspectiva reformista, el rediseño de un Ministerio Público con mayores facultades y recursos en la investigación criminal, y más independiente respecto del Poder Ejecutivo, ayudaría a erradicar algunas de las falencias típicas del poder judicial y los demás actores penales, de manera de estructurar un equipo de investigaciones más imparcial y eficaz ${ }^{4}$.

En Argentina, tanto la jurisdicción nacional como varias provincias registraron reformas en sus sistemas penales basándose en el discurso citado. Sin dudas, por las dimensiones de su sistema penal, y por el grado de transformación experimentado a nivel normativo y burocrático durante las últimas décadas, la reforma de la provincia de Buenos Aires fue la más importante de todas las sucedidas en éste país. Ahora bien, a más de quince años del comienzo de su implementación, todavía no existe un conjunto de estudios que examine sus consecuencias para la protección y promoción de los derechos de los ciudadanos.

Situado en dicho contexto, este trabajo se propone tres objetivos: 1) analizar cómo la nueva normativa de la investigación criminal buscó defender y promover los derechos de los ciudadanos desde 1997 hasta nuestros días; 2) examinar la implementación de la reforma normativa; 3 ) evaluar el impacto de dicha implementación en el acceso a la justicia. La tesis central del trabajo es que pese a la retórica de la dirigencia que reformó la organización de la persecución penal, y a los cambios acontecidos a favor de un Ministerio Público independiente del Poder Ejecutivo y con más recursos y facultades investigativas, la persecución penal ha incrementado la criminalización de las infracciones que realizan los sectores más vulnerables de la población, dejando de lado ilícitos graves como la corrupción política y la violencia policial.

2 Cfr. BINDER, Alberto, "La reforma de la justicia penal: entre el corto y el largo plazo", Sistemas Judiciales, 2 , 3 (2002), Argentina; DUCE, Mauricio, El ministerio público fiscal en la reforma procesal penal en América latina: visión general acerca del estado de los cambios, Chile: CEJA, 2005; y CENTRO DE ESTUDIOS SOBRE LA JUSTICIA DE LAS AMÉRICAS (CEJA), Desafios del Ministerio Público Fiscal en América Latina, Chile: CEJA, 2007.

${ }^{3}$ LANGER, "Revolución", cit. nota ${ }^{\circ}$ 1, p. 617.

${ }^{4}$ Cfr. BINDER, "La reforma", cit. nota n 2, DUCE, El ministerio público fiscal, cit. nota n ${ }^{\circ}$. 
Polít. crim. Vol. 10, No 20 (Diciembre 2015), Art. 4, pp. 528-542.

[http://www.politicacriminal.cl/Vol_10/n_20/Vol10N20A4.pdf]

\section{La reforma acusatoria en la provincia de Buenos Aires.}

Los planes de modernización del sistema de persecución penal en Argentina surgieron junto con el regreso a la democracia. Al poco tiempo de iniciadas las gestiones del presidente radical Raúl Alfonsín y de su correligionario, el gobernador bonaerense Alejandro Armendáriz, dichos mandatarios se hicieron eco de las ideas de prestigiosos juristas, e instalaron en la agenda pública la idea de reformar el sistema inquisitivo tradicional, por uno que adoptase el juicio oral y público, con una reformulación del papel de la fiscalía en la investigación preliminar. La propuesta implicaba una nueva infraestructura ágil y dinámica, con tribunales de constitución rotativa, sistema de jurados o jueces accidentales, servicio oficial de defensa a cargo de los colegios de abogados con participación económica del Estado, y servicio oficial de peritos ${ }^{5}$. Ahora bien, la creciente conflictividad social y política que sufrió el gobierno radical a nivel nacional y bonaerense, interceptó los planes del presidente y del gobernador, obligando a que su implementación se limitara a materializar el juicio oral para los delitos dolosos en los que se hubiera causado la muerte de una persona.

Recién una década más tarde, durante 1997, el gobernador bonaerense Eduardo Duhalde, apoyado por una heteróclita coalición de actores preocupados por el aumento de los delitos y de las denuncias de corrupción y violencia policial ${ }^{6}$, retomó el discurso reformista, y se embarcó en un ambicioso plan que en diez años transformaría sustancialmente la administración de justicia del Estado provincial. En pocos meses, el gobierno bonaerense logró promulgar las normas fundamentales que encuadraron el nuevo modelo acusatorio de persecución penal: las leyes 11.868 (del Consejo de la Magistratura), 11.922 (Código Procesal Penal acusatorio), 12.061 (Orgánica del Ministerio Público), 12.154 (de Seguridad Pública) y 12.155 (de Organización de las Policías de la Provincia de Buenos Aires).

Como señalamos más arriba, un punto clave de la reforma fue el nuevo rol del Ministerio Público y su articulación con las demás instituciones penales. La normativa del Ministerio Público tiene como primera característica ordenar la autonomía e independencia del organismo para que cumpla con su función requirente, pero sin conferirle autarquía. En efecto, el Procurador general y el Subprocurador General, al igual que los miembros de la Suprema Corte de Justicia, son designados por el Poder Ejecutivo con acuerdo del Senado otorgado en sesión pública por mayoría absoluta de sus miembros. La normativa les da estabilidad en el cargo, y sólo pueden ser suspendidos o removidos en caso de acusación mediante el procedimiento que dispone la Constitución. El resto de los cargos jerárquicos del Ministerio Público son seleccionados a través de un concurso de oposición y antecedentes por el Consejo de la Magistratura de la provincia de Buenos Aires ${ }^{7}$. Los recursos económicos del Ministerio Público no provienen de una partida presupuestaria propia; surgen del presupuesto general del Poder Judicial. Ahora bien, la Ley Orgánica prevé "una partida especial para atender los gastos que demanden el equipamiento de los

\footnotetext{
${ }^{5}$ BABINI, Pablo, “La policía en democracia”, Todo es Historia $\mathrm{N}^{\circ} 272$ (1990), Buenos Aires.

${ }^{6}$ Entre los casos más resonantes de violencia y corrupción policial de la época se pueden registrar las denuncias sobre los vínculos de policías bonaerenses con el atentado a la Amia, con el asesinato del periodista José Luis Cabezas, y con varios casos de gatillo fácil y de espionaje a militantes de izquierda.

${ }^{7}$ CEJA, Desafíos del Ministerio Público, cit. nota ${ }^{\circ} 2$, p. 20.
} 
COSTANTINO, Gabriel. "Reforma acusatoria y acceso a la justicia en la provincia de Buenos Aires (Argentina)".

órganos, la capacitación de sus miembros, el sostenimiento de programas de asistencia y protección a la víctima, testigos e incapaces y el debido cumplimiento de sus funciones" (Art. 7 de la Ley 12061). Asimismo el Ministerio Público puede recaudar recursos propios mediante la ejecución de honorarios y costas regulados en su favor y las multas impuestas como pena en los procesos penales ${ }^{8}$.

Una segunda característica importante de la nueva normativa es estructurar jerárquicamente al Ministerio Público; rigiéndolo por los principios de unidad, indivisibilidad, flexibilidad y descentralización. Siguiendo éstos principios, el Procurador General tiene por función organizar el Ministerio Público Fiscal y definir las líneas de persecución penal, para lo cual la ley le otorga la facultad de dictar instrucciones generales. Las mismas se deben regir por el criterio de eficacia (esto es, orientación de la persecución penal a determinadas categorías de delitos, mayores recursos a los mecanismos de simplificación y abreviación de los procesos, etc.), son de carácter público y de cumplimiento obligatorio, y deben ser impartidas en forma escrita. Inmediatamente por debajo de la Procuraduría General se encuentra la Fiscalía de Casación, cuya función principal es tramitar los recursos que lleguen a esa instancia y ejercer las potestades disciplinarias internas (sólo correctivas, no expulsivas). Finalmente, el Ministerio Público desempeña su misión procesal a través de dieciocho fiscalías generales, una por cada departamento judicial en que se divide la provincia 9 .

Las fiscalías generales de cada departamento judicial están a cargo de un fiscal de cámara con facultades amplias para adecuar la organización del Ministerio Público a las exigencias de su distrito. Cada una de ellas tiene una Mesa General de Entradas que se ocupa de recibir las denuncias (tanto en forma directa al público como a partir de la centralización y registro de todos los partes policiales de iniciación de causas que llegan desde las comisarías de la jurisdicción) y distribuirlas entre las distintas Unidades Funcionales de Investigación (en adelante, "UFI"). Por otra parte, esta oficina se ocupa del procedimiento de archivo de expedientes y legajos, de la orientación al público y elaboración de estadísticas, y debe llevar un registro de las personas privadas de libertad y otro en el que constan los datos de aquellos a quienes se les suspende el procedimiento a prueba ${ }^{10}$.

Los fiscales generales departamentales deben organizar en su distrito un cuerpo de fiscales que lleve adelante las investigaciones penales preparatorias, organizados en una serie de unidades fiscales de instrucción y un cuerpo de fiscales para la etapa del juicio. Según la normativa que se acumula desde 1998, la organización de la investigación criminal debe ser flexible y dinámica, y las oficinas fiscales pueden ser asignadas para cumplir sus funciones en lugares distintos de aquellos en los que tuviere asiento la sede departamental, pues esto conllevaría un mejor cumplimiento del servicio, con mayor sensibilidad a las demandas de la comunidad ${ }^{11}$.

\footnotetext{
${ }^{8}$ CENTRO DE ESTUdiOS LEGALES Y SOCIALES (CELS), Políticas de seguridad ciudadana y justicia penal, Buenos Aires: Siglo XXI Editores, 2004, pp. 60 y 61.

${ }^{9} \mathrm{Cfr}$. http://www.mpba.gov.ar/web/institucional.php

${ }^{10}$ CELS, Políticas de seguridad, cit. nota $\mathrm{n}^{\circ} 8, \mathrm{p} .62$.

${ }^{11}$ CELS, Políticas de seguridad, cit. nota n ${ }^{\circ}$ 8, p. 62 y http://www.mpba.gov.ar/web/institucional.php
} 
Polít. crim. Vol. 10, No 20 (Diciembre 2015), Art. 4, pp. 528-542.

[http://www.politicacriminal.cl/Vol_10/n_20/Vol10N20A4.pdf]

\section{La implementación de la nueva normativa.}

A fin de lograr los objetivos de la nueva normativa, el Ministerio Público debía contar además de con las nuevas facultades, con mayores recursos económicos y humanos. En efecto, durante 1998 se puso en funcionamiento el Consejo de la Magistratura y el sistema acusatorio, con un presupuesto incrementado y con una creciente planta de personal. Mientras que en 1997 había 348 magistrados en el fuero penal, 69 fiscales y 9.000 empleados, y el presupuesto para el área era de 116 millones de pesos anuales, cuatro años después, la cantidad de jueces penales designados pasó a 1.023, la de fiscales a 426, y los administrativos pasaron a ser 15.248. Todo esto con un presupuesto de 595 millones de pesos para hacer frente a los gastos de funcionamiento ${ }^{12}$.

Más allá de los cambios de gobernador que se sucedieron hasta la actualidad, y de las diferentes orientaciones de las políticas de seguridad y penales ${ }^{13}$, los ejecutivos provinciales coincidieron en profundizar la reforma acusatoria aumentando permanentemente los recursos humanos y económicos del Ministerio Público, y del resto del sistema de persecución penal. Las gestiones de Eduardo Duhalde, Carlos Ruckauf, Felipe Solá y Daniel Scioli, se diferenciaron en muchos puntos, sin embargo, todos coincidieron en invertir en esta nueva burocracia, que en quince años casi triplicó su planta de personal.

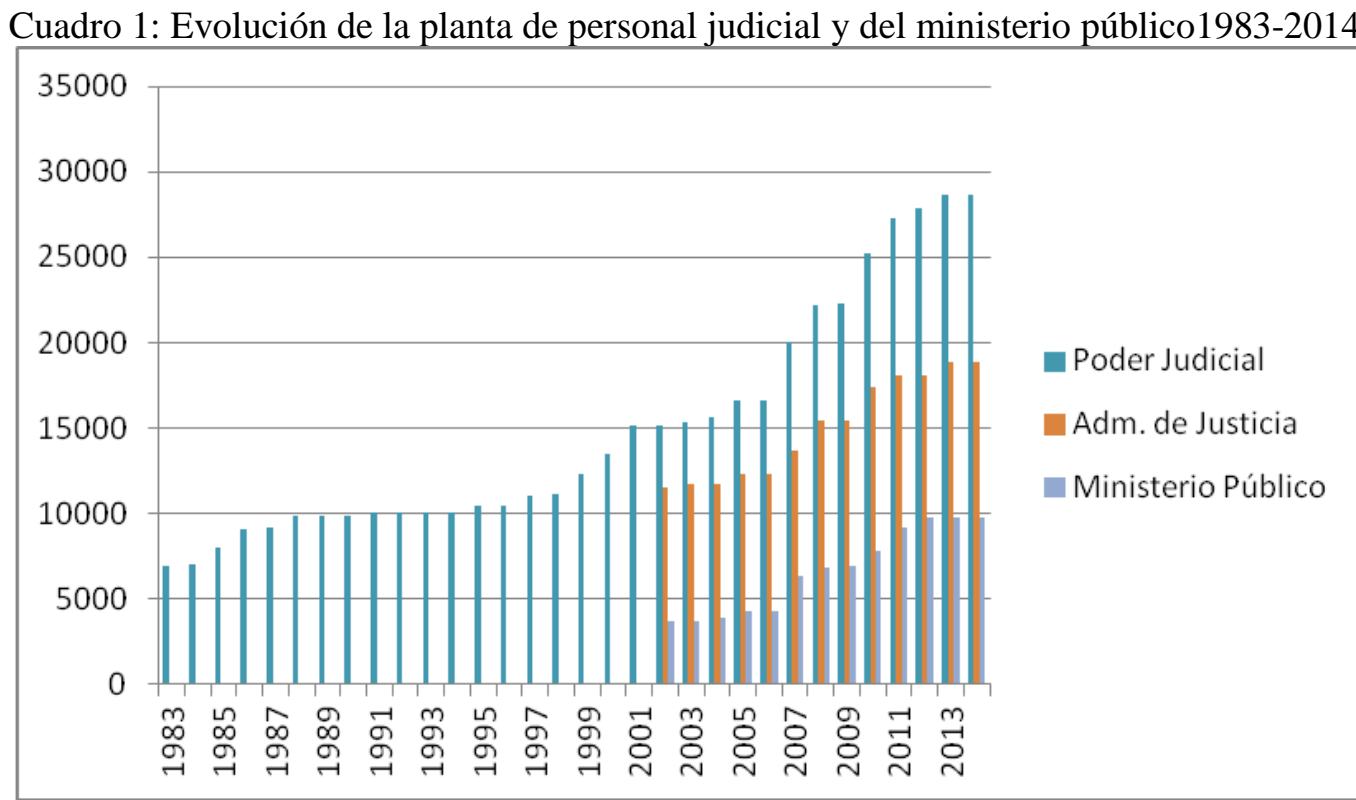

Fuente: Elaboración propia a partir de datos del Ministerio del Interior (Provinfo).

Vinculado a esta convergencia entre los gobernadores, se destacan dos políticas penales que perduraron en el tiempo y que afectaron profundamente la persecución criminal y la

\footnotetext{
${ }^{12}$ Diario La Nación 2007.

${ }^{13}$ Para el análisis de las diferentes políticas de seguridad y penales bonaerenses, ver COSTANTINO, Gabriel, "La autonomía policial en cuestión: Gobernadores y políticas de seguridad en cuatro provincias argentinas", Aposta Digital Nro. 63 (2014), ISSN 1696-7348.
} 
COSTANTINO, Gabriel. "Reforma acusatoria y acceso a la justicia en la provincia de Buenos Aires (Argentina)".

naturaleza de su eficacia: la desconcentración de las fiscalías y el fortalecimiento de la persecución penal de casos en "flagrancia".

\subsection{La desconcentración de fiscalías.}

Como vimos más arriba, uno de los puntos importantes de la reforma organizativa del Ministerio Público implicaba que las fiscalías generales de cada departamento judicial tenían amplias facultades para adecuar la organización a las exigencias de su distrito. A partir de 1999, dos fiscalías departamentales se destacaron por establecer una organización original de su burocracia: los departamentos judiciales de San Isidro y de Gral. San Martín ${ }^{14}$.

En el departamento judicial de San Isidro, el Fiscal General se reunió con los intendentes de los cinco municipios que comprende dicho distrito (Pilar, Tigre, San Isidro, San Fernando y Vicente López) y les propuso un plan de descentralización de las UFIs que se ha desarrollado desde 1999 hasta nuestros días. El plan consiste en un modelo de gestión que tiene dirección y control centralizado, por un lado, y regionalización de las prestaciones de servicio por el otro, buscando tener conocimiento directo de las problemáticas locales, lograr la actuación inmediata por la cercanía geográfica, y evitar la delegación de diligencias procesales en la policía. La desconcentración de las UFIs lograría mejorar entonces (i) el conocimiento de los delitos prioritarios, (ii) la agilización de las investigaciones penales, y (iii) el control de la actividad estatal (principalmente de la policía).

En el departamento judicial de Gral. San Martín la decisión innovadora de la fiscalía general fue organizar las UFIs especializándolas en los distintos tipos de delitos, a la vez que se fortalecían en recursos a aquellas encargadas de investigar delitos complejos como las estafas, las defraudaciones, el libramiento de cheques sin fondos y los delitos de la administración pública. El supuesto que explica este tipo de organización de las UFIs es que existe un segmento de delitos prioritarios que no pueden ser investigados de igual modo que los casos típicos de robos y violencia contra las personas, y que necesitan un tratamiento diferente de parte de los fiscales ${ }^{15}$.

Diez años después de la puesta en práctica de las dos estrategias en estos departamentos judiciales, es evidente que la estrategia de la desconcentración es la opción que se diseminó por toda la provincia. En efecto, a finales de 2004, a través de la ley 13.274, la estrategia de desconcentración se transformó en el Programa de Descentralización de Fiscalías, Defensorías y Ayudantes Fiscales. Según el Ministro de Justicia y la Procuradora General, el programa es una "política de Estado", compartida por el Ejecutivo, la Legislatura, el Poder Judicial y los gobiernos locales ${ }^{16}$. Sólo desde 2005 al 2007 se han invertido en el

\footnotetext{
${ }^{14}$ CELS, Políticas de seguridad, pp. 64-66.

${ }^{15}$ CELS, Políticas de seguridad, pp. 64-66.

${ }^{16}$ Según declaraciones de Eduardo Di Rocco, "esta política de descentralización tiene un claro perfil de política de Estado y hay un trabajo muy fuerte, muy importante, acá han sido clave varios actores, las Cámaras de Diputados, de Senadores, la Procuración con un equipo eficiente y muy audaz, el Concejo de la Magistratura de la provincia de Buenos Aires, el Concejo Deliberante que autorizo esta inversión y
} 
programa millones de pesos que son financiadas por el poder judicial y los gobiernos municipales, y se han abierto más de 180 fiscalías, defensorías y ayudantías fiscales en los puntos más remotos de la Provincia de Buenos Aires ${ }^{17}$.

En oposición a la suerte corrida por la estrategia de desconcentrar fiscalías, la estrategia de especializar el trabajo de las UFIs y fortalecer las investigaciones en delitos complejos no fue apoyada e incluso fue "desactivada". El único caso en la estructura judicial bonaerense que experimentó un cambio importante en su modelo organizativo para concentrar mayores recursos en las investigaciones complejas y de corrupción política fue obstaculizado y fustigado por distintos funcionarios estatales de primer nivel. En efecto, en el año 2006, la política de Estado terminó de manifestar su coherencia con la intervención de la Procuraduría General sobre la fiscalía departamental de Gral. San Martín ${ }^{18}$.

\subsection{El fortalecimiento del sistema acusatorio (o mejor, de la persecución penal de casos de "flagrancia").}

La segunda política específica que se destaca de las llevadas adelante desde la cúpula del sistema penal para perseguir eficazmente delitos prioritarios es el plan para el fortalecimiento del sistema acusatorio de la Provincia de Buenos Aires. Este plan nació con un convenio elaborado en el 2004 por el Centro de Estudios Judiciales para las Américas (CEJA), la Procuración General y la Suprema Corte de Justicia de la Provincia de Buenos Aires, el Ministerio de Justicia bonaerense y el Instituto de Ciencias Sociales y Penales (INECIP). Dicho programa puso en marcha un plan piloto en 2005 en el departamento judicial de Mar del Plata, al que luego se incorporaron los departamentos judiciales de Zárate/Campana, Mercedes, Necochea, Trenque Lauquen, Junín, La Matanza y San Martín. En febrero de 2008 el programa se convirtió en ley y se extendió a todo el territorio.

El objetivo fundamental del convenio fue introducir un nuevo procedimiento para la resolución de los casos de flagrancia basado en un modelo de tramitación en el que se oralizan la etapas preliminares del proceso, permitiendo el planteo en audiencias, de salidas tempranas alternativas al juicio. Este nuevo procedimiento lograría la agilización de las causas en enjuiciamiento penales para delitos flagrantes, elevando la calidad de soluciones alcanzadas (con incorporación efectiva y plena de la oralidad e inmediación), aligerando a su vez la carga de trabajo de los distintos organismos componentes de la estructura judicial.

En efecto, el nuevo procedimiento para los casos de flagrancia está previsto para juzgar y eventualmente condenar a los autores de delitos con penas menores a los 15 años como el hurto y la tentativa de robo y que han sido aprehendidos en el mismo momento de su ejecución, inmediatamente después de haberlo perpetrado, en el curso de una persecución policial o al ser sorprendidos portando alguno de los objetos relacionados con su comisión. Se establece un proceso muy breve de acusación, fijándose un plazo máximo de 60 días para dictar sentencia, una vez que la causa es elevada a juicio oral. Antes de la elevación a

naturalmente la decisión política del gobierno local y de su intendente que estaba en todos los lugares que podía estar para impulsar la instalaciones de estas defensorías" (Diario Novedades 2007).

${ }^{17}$ Diario Novedades 2007, Prensa Municipal de Ituzaingo.

${ }^{18}$ Diario Página 2006. Revista En Marcha 7/2008. 
COSTANTINO, Gabriel. "Reforma acusatoria y acceso a la justicia en la provincia de Buenos Aires (Argentina)".

juicio, se puede pactar una pena con el imputado. Todo el proceso es oral. Se trata de eventos cuya averiguación no exigen de una investigación previa del fiscal y que, en la mayoría de los casos, son delitos contra la propiedad en todas sus modalidades.

Al igual que con el programa de desconcentración de fiscalías, el programa flagrancia obtuvo el respaldo de las autoridades del poder ejecutivo y judicial, y de la mayoría de los legisladores de los partidos políticos más importantes de la provincia. El motivo también se repite entre todos ellos: el nuevo procedimiento sirve para descongestionar el cuello de botella de las fiscalías de instrucción, acelerar el ajusticiamiento de la delincuencia común y combatir el flagelo de la inseguridad.

\section{Las consecuencias para el acceso a la justicia.}

El concepto de acceso a la justicia tiene múltiples acepciones, pero todas se vinculan con cómo diversos factores afectan la brecha entre lo que dice la ley y lo que sucede efectivamente en las prácticas sociales ${ }^{19}$. En general, los trabajos sobre acceso a la justicia hacen hincapié en la falta de conocimiento de la ciudadanía sobre sus derechos o en la falta de recursos -o en la existencia de obstáculos- para iniciar una causa y llevarla adelante en los tribunales. Ahora bien, desde hace varios años la literatura especializada ha notado un problema para el acceso a la justicia tan o más importante que aquellos: la discrecionalidad de las instituciones penales para investigar y penar los distintos tipos de hecho delictivo ${ }^{20}$. Sucede que en muchos distritos las agencias oficiales se concentran en investigar y castigar las infracciones realizadas por los sectores más vulnerables de la población, dejando de lado delitos prioritarios cometidos por el crimen organizado y/o la administración pública.

En concordancia con la opinión de los especialistas, los legisladores que reformaron el sistema penal bonaerense reconocieron dicho problema en el acceso a la justicia en la Provincia de Buenos Aires, y propusieron como objetivo expreso del Ministerio Público cambiar la dirección del sistema de investigaciones hacia los delitos prioritarios. Si bien este tipo de delito no tuvo nunca límites precisos, se gestó un consenso, explicitado también en la normativa del Ministerio Público, de que los fiscales deberían brindar especial atención a los hechos delictivos vinculados con torturas, apremios ilegales y delitos económicos que afecten el interés colectivo, como asimismo a los delitos cometidos por funcionarios públicos en el ejercicio de sus atribuciones ${ }^{21}$.

Paradójicamente, las principales estrategias implementadas por la Procuraduría General -y apoyada como "política de Estado" por las cúpulas de los poderes gubernativos- no sirven para la persecución de los delitos de corrupción y del crimen organizado. Por ejemplo, la desconcentración de fiscalías tiene la virtud de acercar recursos humanos a la comunidad

\footnotetext{
${ }^{19}$ RICO, Justicia penal y transición, cit. nota $n^{\circ} 1$; BRINKS, Daniel, Legal Tolls and the Rule of Law: The Judicial Response to Police Killings in South America, Dissertation, Estados Unidos: University of Notre Dame, 2004. GARGARELLA, Roberto, Too far removed from the people. Access to Justice for the Poor: The Case of Latin America, 2002.

${ }^{20}$ MENDEZ/O`DONNELL/PINHEIRO, La (in)efectividad, cit. nota ${ }^{\circ} 1$, BRINKS, Legal Tolls, cit. nota ${ }^{\circ}$ 19. MARCHISIO, Adrián, "Principio de Oportunidad, sinceramiento del sistema y desafíos para el Ministerio Público Fiscal”, Revista del Ministerio Público Fiscal, Núm. 12 (2003), Argentina.

${ }^{21}$ Resolución 1390 del Procurador General, 10/12/2001.
} 
para que ésta tenga menores costos para iniciar una causa y llevarla adelante en los tribunales. Pero esta estrategia no promueve un papel más activo y selectivo del fiscal, sino que replica el rol pasivo del sistema inquisitorio criticado por toda la doctrina reformista. Entonces, el flujo de causas que ingresa son los generados por la policía y los particulares; éstas consisten, esencialmente, en delitos comunes -la mayoría de las veces menorescontra la propiedad y la integridad física.

\section{Como bien explica Cruz Castro:}

“(...) los delitos de corrupción y muchas estafas son delitos sin víctimas, por esta razón difícilmente el conocimiento de estos hechos llegará a conocimiento de las autoridades competentes mediante la denuncia común, tal como ocurre, por ejemplo, en los delitos contra la integridad física." 22

Mendaña señala complementariamente que tampoco las instituciones policiales suelen considerar entre sus objetivos la investigación de los delitos económicos, de corrupción pública o violencia estatal. En efecto, ciertos segmentos de la criminalidad no son considerados por las agencias policiales ni por la ciudadanía común. A raíz de ello, es responsabilidad del Ministerio Público contar con cierta capacidad propia para identificar, investigar y perseguir la criminalidad no tradicional, si es que se pretende cumplir con su función de promotor de la justicia y la legalidad ${ }^{23}$.

Estos especialistas coinciden en que el Ministerio Público debe desplegar una estrategia diferente frente a los delitos complejos, dejando de esperar que le lleguen los datos de la policía o los particulares. "El fiscal debe iniciar, de oficio, las pesquisas, planificando, incluso, labores de investigación preventiva, acumulando pacientemente datos y referencias para poder organizar, con el rompecabezas de la información, una hipótesis de investigación que luego le permita definir la acusación"24. Para ello necesita de recursos humanos con alta capacitación profesional (detectives, contadores, analistas de sistemas y otros expertos), fuentes de información adecuadas (acceso a registros públicos y privados), coordinación con otros entes públicos encargados de ejercer funciones de control de la Administración Pública (contralorías, etc.), facultades para revisar las acciones y cuentas de las burocracias, presupuesto adecuado, una división del trabajo inteligente con la policía, etc.

La selectividad del sistema de persecución penal hacia los delitos menores cometidos por los sectores más vulnerables de la población se incrementa con el plan de fortalecimiento del sistema acusatorio. Pablo Poggeto, fiscal de delitos económicos en Mar del Plata y especialista en derecho procesal, explica que el nuevo procedimiento de "flagrancia" es útil para enfrentar aquellas causas dónde la investigación se resuelve sólo con el acta policial.

22 CRUZ CASTRO, Fernando, "La investigación y persecución de la corrupción. Observaciones fundamentales sobre el rol del Ministerio Público en los sistemas penales latinoamericanos", Pena y Estado Nro. 1 (1995), Buenos Aires: Editores del Puerto, pp. 81-88.

${ }^{23}$ MENDAÑA, Ricardo, "El Ministerio Público y la dirección de la investigación criminal”, Cuadernos de derecho penal 2 (2005), Asociación de pensamiento penal, Argentina.

${ }^{24}$ CRUZ CASTRO, "La investigación”, cit. nota $n^{\circ} 22$. 
COSTANTINO, Gabriel. "Reforma acusatoria y acceso a la justicia en la provincia de Buenos Aires (Argentina)".

Pero la policía trae, en el mejor de los casos, los delitos que encuentra, y encuentra a los delincuentes menos preparados. Nunca atrapa a los autores de delitos complejos o miembros del crimen organizado. En efecto, el fortalecimiento de este tipo de persecución penal va a producir estadísticas con más personas aprehendidas, juzgadas, procesadas y condenadas, pero por causas de delitos menores ${ }^{25}$.

Más inquietante aún, para Roberto Cipriano García ${ }^{26}$ y Antonio Cortina ${ }^{27}$, este procedimiento, que incluye la posibilidad de salidas rápidas, puede convertirse en un proceso de negociación entre partes desiguales, dónde los acusados aceptan su culpabilidad en hechos que no cometieron para evitar una estadía larga en la cárcel. En efecto, con el nuevo procedimiento existen mayores posibilidades de prácticas extorsivas por parte de los agentes del sistema penal, a la vez que no se contribuye a frenar el armado de causas por parte de la policía.

Llegado a este punto, y en oposición a los que sostienen que no hay una política de persecución penal del gobierno bonaerense, creo que se debe notar que en esta provincia existe una estrategia de investigación criminal bastante coherente y consensuada. Lo curioso es que dicho plan estratégico ha tomado el camino opuesto al que le señalaba la norma que se había diseñado. La estrategia de la desconcentración de las fiscalías y del programa "flagrancia" avanza en la criminalización de las infracciones que cometen los sectores más vulnerables de la población, dejando de lado los ilícitos que cometen funcionarios públicos y gente acomodada, delitos que muchas veces son bastante más graves que las infracciones de los pobres.

\subsection{Algunos datos del accionar penalizador del Estado.}

El propósito de este apartado es ilustrar el accionar criminalizador del Estado bonaerense antes y durante la implementación de la reforma acusatoria del sistema de persecución penal en la Provincia de Buenos Aires, a partir de finales de 1998. En especial, me interesa mostrar los datos que inducen a pensar que el accionar criminalizador del Estado bonaerense continuó concentrándose en los delitos comunes y no, como hacía suponer la doctrina, en los delitos prioritarios como los de corrupción y/o violencia estatal.

Si uno tiene en cuenta que la implementación de la reforma comenzó gradualmente a partir de 1999, los datos muestran que la cantidad de sentencias condenatorias se van incrementando a medida que pasan los años de la implementación, hasta multiplicarse por 3 respecto del nivel de sentencias en 1998, desde el 2004 en adelante. Algo interesante es que las sentencias condenatorias por delitos contra la propiedad se incrementaron proporcionalmente aún más que las sentencias condenatorias por todos los delitos (casi cinco veces). Pasaron de 2.264 y 1.926 en 1998 y 1999, a 9.638 en 2006, 8.791 en 2007 y 9.370 en $2008^{28}$. Y éste aumento en las sentencias condenatorias se da en un contexto

\footnotetext{
${ }^{25}$ Revista En Marcha Nro. 47, 5/2008.

${ }^{26}$ Coordinador del Comité contra la tortura de la Comisión por la Memoria de la Provincia de Buenos Aires.

${ }^{27}$ Asesor Asociación Judicial Bonaerense.

${ }^{28}$ Lamentablemente los datos disponibles sobre sentencias condenatorias y delitos registrados de la Dirección Nacional de Política Criminal culminan en 2008 para el caso de la Provincia de Buenos Aires.
} 
Polít. crim. Vol. 10, № 20 (Diciembre 2015), Art. 4, pp. 528-542.

[http://www.politicacriminal.cl/Vol_10/n_20/Vol10N20A4.pdf]

dónde los delitos registrados se incrementan en menor medida o incluso disminuyen (ver cuadros 2 y 3 ).

Cuadro 2: Sentencias condenatorias (1991-2008).

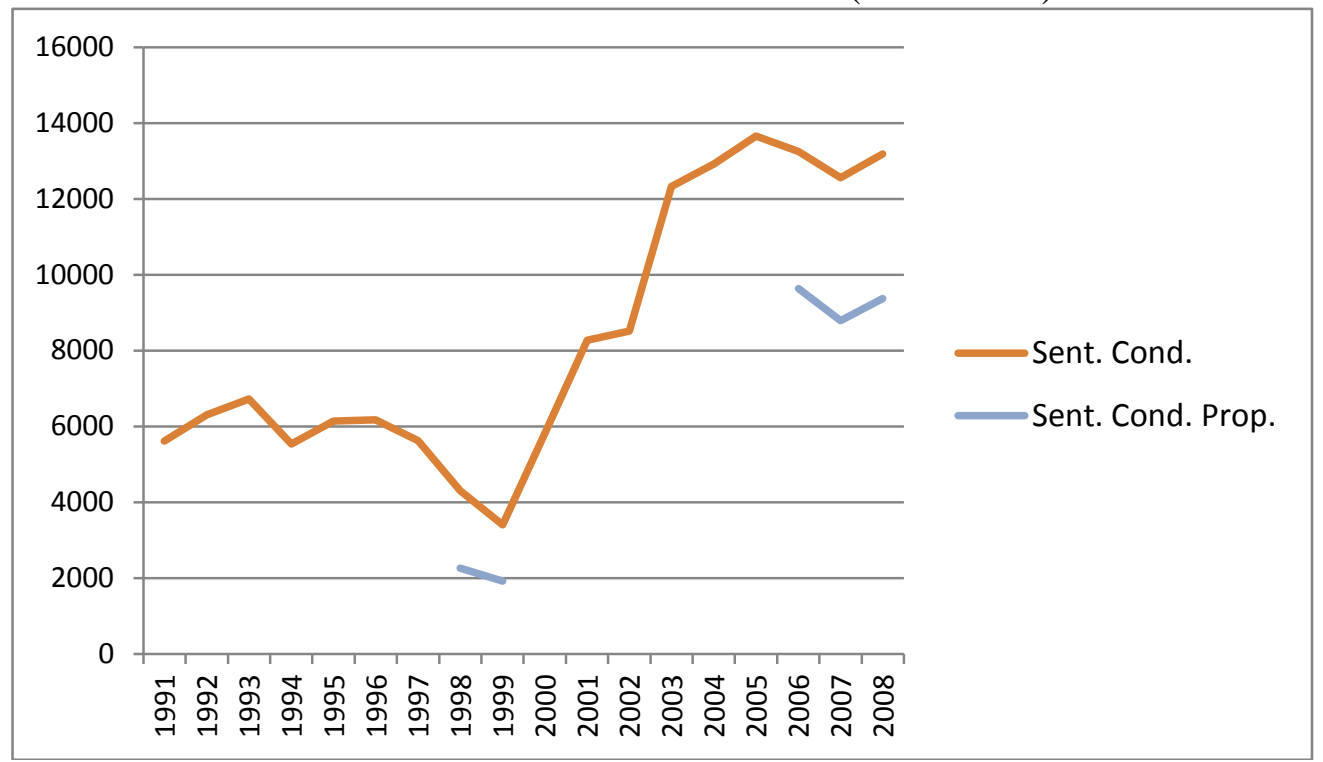

Fuente: Elaboración propia en base a datos del Ministerio de Seguridad (SNEEP).

Cuadro 3: Delitos registrados (1991-2008).

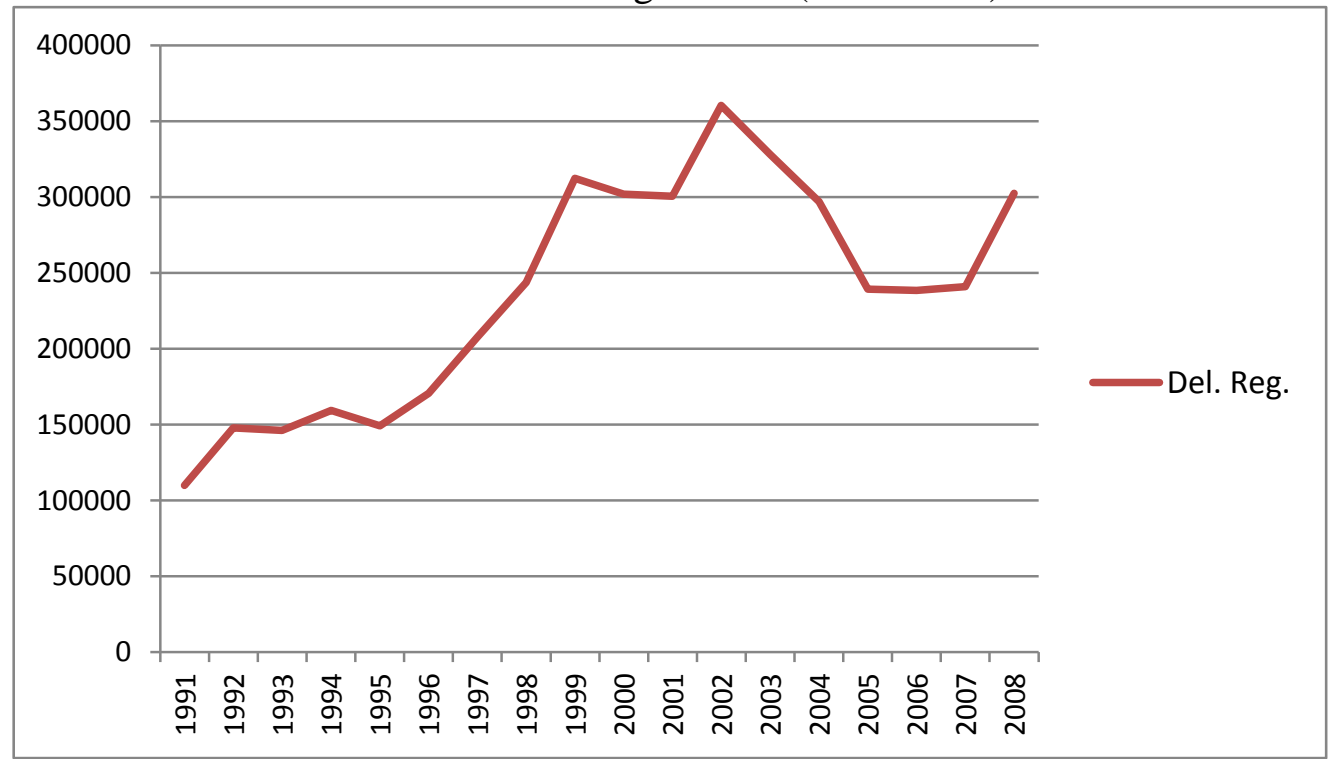

Fuente: Elaboración propia en base a datos del Ministerio de Seguridad (SNEEP).

Sumado a que las sentencias condenatorias se incrementan sustancialmente luego de la implementación de la reforma del sistema penal, los datos recabados por el Centro de Estudio Legales y Sociales a partir de información de la Suprema Corte de Justicia 
COSTANTINO, Gabriel. "Reforma acusatoria y acceso a la justicia en la provincia de Buenos Aires (Argentina)".

bonaerense, constata que las sentencias son cada vez más largas y de cumplimiento efectivo (no condicional) (ver Cuadros 4 y 5).

Cuadro 4: Evolución de condenas privativas de la libertad (1998-2007).

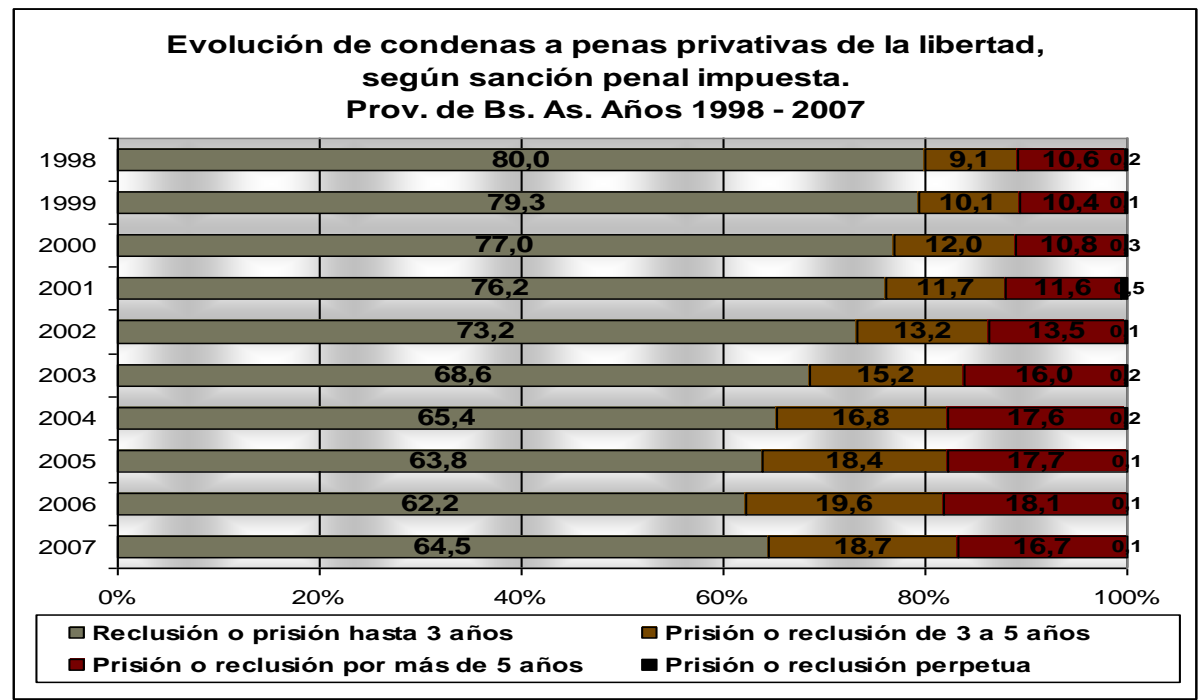

Fuente: CELS, en base a datos del Servicio Penitenciario Bonaerense y de la Superintendencia de Coordinación General del Ministerio de Seguridad de la Provincia de Buenos Aires.

Cuadro 5: Evolución de sentencias según condenas (1998-2007).

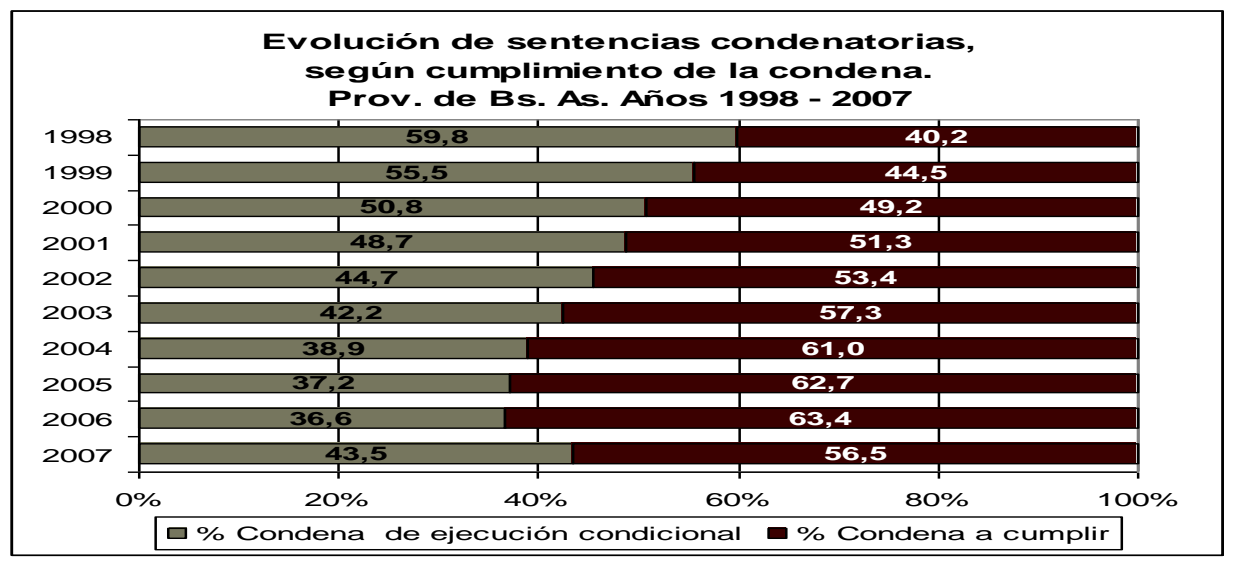

Fuente: CELS, en base a datos del Servicio Penitenciario Bonaerense y de la Superintendencia de Coordinación General del Ministerio de Seguridad de la Provincia de Buenos Aires.

Una consecuencia directa de la reforma y del aumento del nivel de sentencias condenatorias es el incremento sustancial de la población penitenciaria entre 1997 y 2005 . A partir del 2005 se produce una disminución hasta fines de 2007. Allí comienza a aumentar llegando a un punto similar al del 2005. Si comparamos las poblaciones penitenciarias de las principales provincias del país, se nota claramente que Buenos Aires es el distrito dónde el aumento de la cantidad de presos ha sido mayor (Cuadro 6). 
Polít. crim. Vol. 10, No 20 (Diciembre 2015), Art. 4, pp. 528-542.

[http://www.politicacriminal.cl/Vol_10/n_20/Vol10N20A4.pdf]

Cuadro 6: Evolución de población encarcelada (1997-2012).

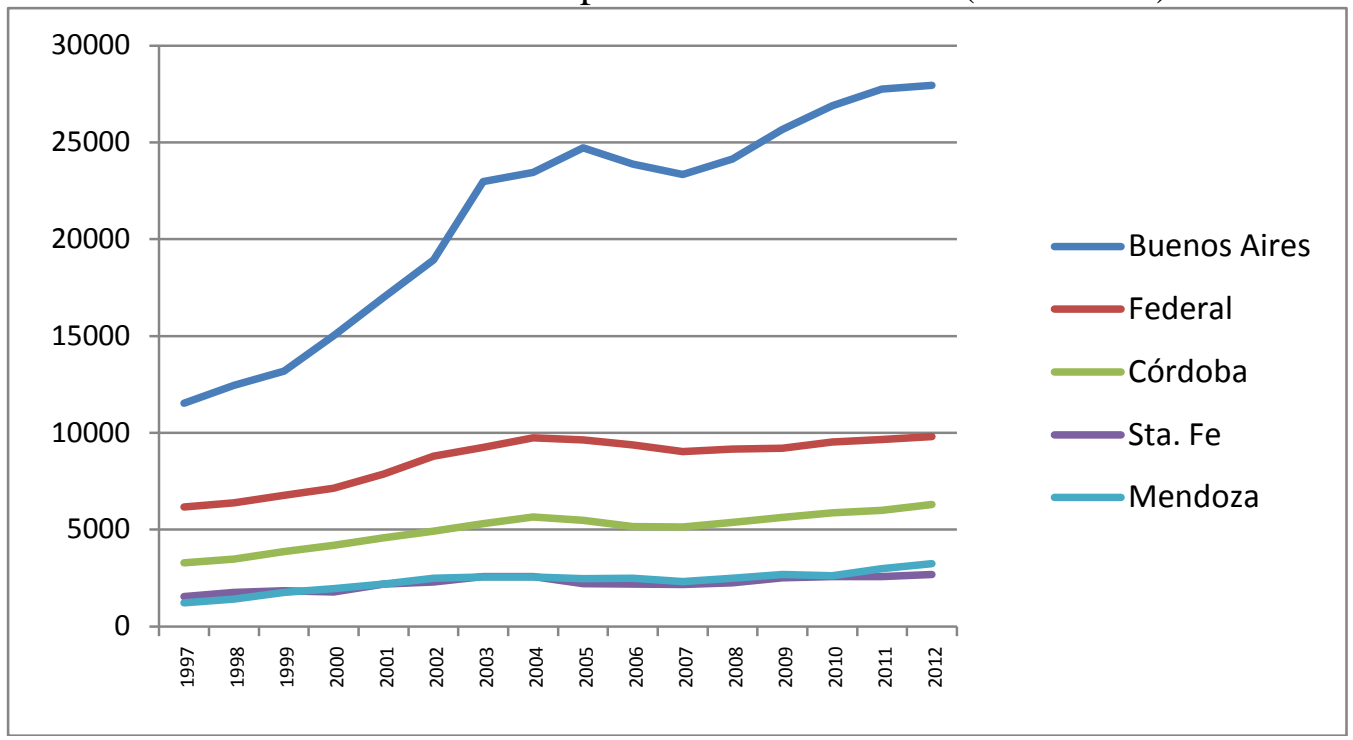

Fuente: Elaboración propia en base a datos del Ministerio de Seguridad (SNEEP).

Aunque existe una leve mejoría del porcentaje de presos en prisión preventiva a partir de 2005, la proporción continúa siendo alarmante.

Cuadro 7: Evolución situación procesal de personas privadas de la libertad (2000-2010).

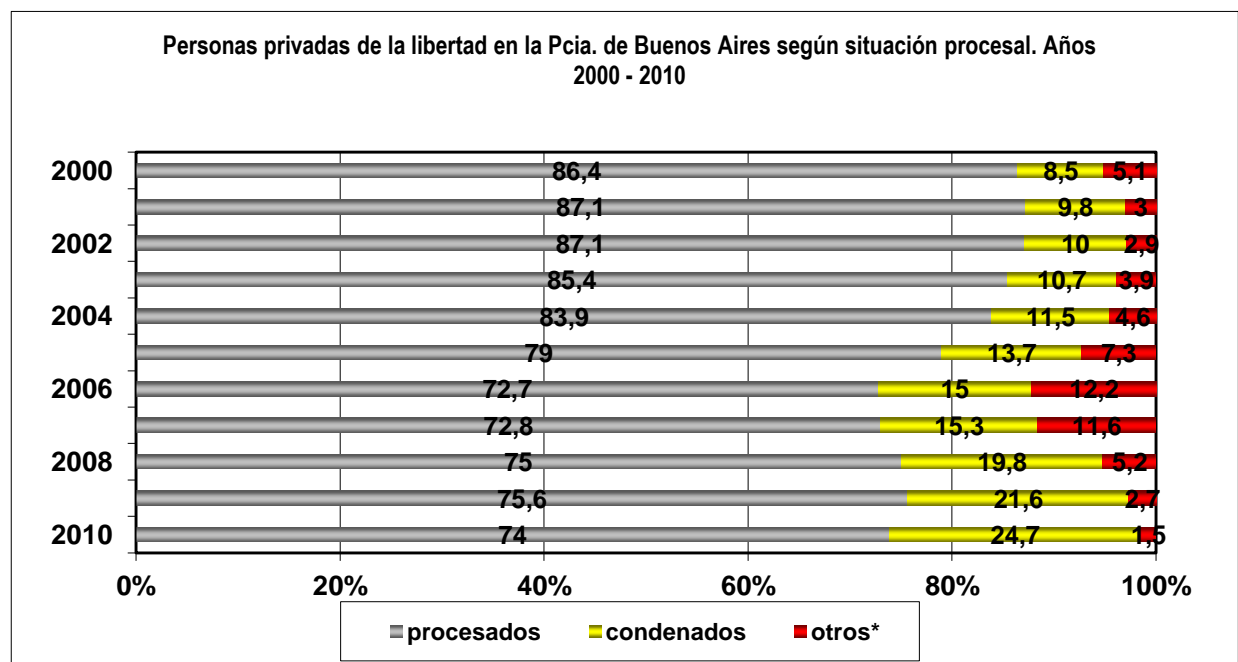

Fuente: CELS, en base a datos del Servicio Penitenciario Bonaerense y de la Superintendencia de Coordinación General del Ministerio de Seguridad de la Provincia de Buenos Aires.

Un dato importante es que este mayor accionar penalizador del Estado bonaerense se da en un momento dónde el nivel de delincuencia común, según las encuestas de victimización y los delitos registrados por la policía, no se ha incrementado.

En contraste con el aumento en el accionar penalizador del delito común, que se manifiesta en el incremento de las sentencias condenatorias y en la cantidad de personas privadas de 
COSTANTINO, Gabriel. "Reforma acusatoria y acceso a la justicia en la provincia de Buenos Aires (Argentina)".

su libertad, la persecución penal de los delitos de violencia estatal como los apremios ilegales, las torturas y los homicidios cometidos por fuerzas de seguridad no han aumentado con la implementación de la reforma acusatoria.

Según un informe de la Secretaría de Derechos Humanos de la Provincia de Buenos Aires $^{29}$, la respuesta penal ante este tipo de delitos durante 1998 y 2002 fue prácticamente nula. En este informe se analizaron 3013 causas iniciadas y tramitadas entre 1998 y principios de 2002, cuyas carátulas refieren a delitos de torturas y apremios ilegales. De este universo de causas, en el $64 \%$ de los casos (1921) se estimó que no había mérito para acusar (1856 fueron archivadas, 54 desestimadas, 3 sobreseídas, 7 desistidas y 1 suspendida al juicio a prueba). El 35\% de las causas (1062) se encontraban en trámite, y sólo el 1\% (30) habían sido elevadas a juicio.

Según la base de datos del Comité Contra la Tortura de la Comisión Provincial por la Memoria, la respuesta penal frente a estos delitos no mejoró con los años y la implementación (y la contratación de fiscales). Entre el 2000 y el 2008, la Comisión ha recibido información sobre 10.936 causas judiciales originadas en denuncias contra delitos cometidos por integrantes de las fuerzas de seguridad bonaerenses ${ }^{30}$. También en esta base se repite la cifra ínfima de un $1 \%$ para los casos de causas que son elevadas a juicio.

Finalmente, existe una tercera fuente de información implementada hace poco tiempo que puede ser muy útil en un futuro para el seguimiento de la persecución penal de estos tipos de delitos: el Sistema de Información del Ministerio Público (SIMP). Si bien esta última fuente no está elaborando todavía informes sistemáticos y públicos, por datos comunicados a la Comisión Contra la Tortura, sabemos que durante 2009 ingresaron 4.861 causas sobre este tipo de delitos. De esta muestra, mucho más exhaustiva que las anteriores, sabemos que para abril de 2010 el $20 \%$ ya estaban archivadas, y sólo en un 0,25 de los casos habían sido elevados a juicio.

\section{Conclusiones.}

Como adelantamos en la introducción, este trabajo se propuso tres objetivos: i) analizar cómo la reforma legal del sistema de persecución criminal buscó defender y promover los derechos de los ciudadanos desde 1997 hasta nuestros días; ii) examinar cómo se implementó la reforma del sistema de persecución penal; iii) evaluar el impacto de dicha implementación en el acceso a la justicia. Las principales conclusiones que se derivan de la investigación son las siguientes:

Sobre el primer punto sostuvimos que, pese a las múltiples interpretaciones que pueden hacerse sobre el espíritu y finalidad de las leyes en general, la reforma del sistema de persecución penal bonaerense implicaba claramente un compromiso con la independencia del Ministerio Público respecto del Poder Ejecutivo, el acrecentamiento de sus facultades y recursos para la persecución penal, y la investigación más ágil y eficaz de los delitos

\footnotetext{
29 "El tratamiento de la tortura ante el sistema penal de la Provincia de Buenos Aires", en el marco del Programa provincial de prevención de la tortura (creado por decreto 1404/02).

${ }^{30}$ Este trabajo de la Comisión fue apoyado por la resolución 382/04 de la Suprema Corte de Justicia.
} 
Polít. crim. Vol. 10, No 20 (Diciembre 2015), Art. 4, pp. 528-542.

[http://www.politicacriminal.cl/Vol_10/n_20/Vol10N20A4.pdf]

socialmente relevantes. En segundo lugar, notamos que si bien la categoría de "delito prioritario" no tiene límites precisos, existe un consenso entre los especialistas, explicitado en la normativa del Ministerio Público, de que los fiscales deberían brindar máxima atención a los hechos delictivos vinculados con torturas, apremios ilegales y delitos económicos que afectan el interés colectivo, como asimismo a los delitos cometidos por funcionarios públicos en el ejercicio de sus atribuciones.

Respecto al segundo punto, señalamos que a partir de 1999 se destaca el crecimiento de recursos económicos y humanos en el sistema de persecución penal, y la puesta en marcha de dos políticas prioritarias: (i) la desconcentración de las fiscalías y (ii) el fortalecimiento de la persecución penal de delitos en "flagrancia". Estos cambios en la estructura y el funcionamiento del Ministerio Público han sido apoyados y promovidos por organismos internacionales, de la sociedad civil, las autoridades de los tres poderes del Estado bonaerense, además de los intendentes y concejales de los partidos políticos más importantes de la provincia.

Finalmente, respecto al último punto, argumentamos que mejorar el acceso a la justicia implica responder a la problemática de la selectividad de la persecución penal de manera de investigar y penalizar los delitos prioritarios. Luego notamos que la estrategia de la desconcentración de fiscalías y del fortalecimiento de la persecución penal de delitos en "flagrancia" llevaba a resultados contrarios a los objetivos de la normativa reformista, y a la promoción del acceso a la justicia. Según la opinión de los especialistas, estas estrategias promovidas como políticas de Estado avanzan en la criminalización de las infracciones que cometen los sectores más vulnerables de la población -no importa su envergadura-, dejando de lado los ilícitos graves que cometen funcionarios públicos y gente acomodada. En esta línea, la política del Estado bonaerense relativa a la persecución penal no sólo promueve una estrategia investigativa contraria al acceso a la justicia, sino que ha desactivado las iniciativas de las Fiscalías Generales que organizan a sus UFIs de acuerdo a las recomendaciones de los especialistas.

Por supuesto, este trabajo es una primera aproximación al problema de la reforma del sistema de persecución penal y el acceso a la justicia en la provincia de Buenos Aires. Entendemos que hay que continuar con las investigaciones profundas y sistemáticas sobre los factores que explican la situación actual de la persecución penal y las posibilidades de cambiar su dirección para mejorar su eficacia y equidad. 
COSTANTINO, Gabriel. "Reforma acusatoria y acceso a la justicia en la provincia de Buenos Aires (Argentina)".

\section{BIBLIOGRAFÍA}

BABINI, Pablo, "La policía en democracia", Todo es Historia № 272 (1990), Buenos Aires.

BINDER, Alberto, "La reforma de la justicia penal: entre el corto y el largo plazo", Sistemas Judiciales 2, (2002), Argentina.

BRINKS, Daniel, Legal Tolls and the Rule of Law: The Judicial Response to Police Killings in South America, Dissertation, University of Notre Dame, 2004.

CENTRO DE ESTUDIOS LEGALES Y SOCIALES (CELS), Políticas de seguridad ciudadana y justicia penal, Buenos Aires: Siglo XXI Editores, 2004.

CENTRO DE ESTUDIOS SOBRE LA JUSTICIA EN LAS AMÉRICAS (CEJA), Reformas procesales penales en América Latina: Resultados del proyecto de seguimiento, Chile: CEJA, 2005.

Desafíos del Ministerio Público Fiscal en América Latina, Chile: CEJA, 2007.

COSTANTINO, Gabriel, "La autonomía policial en cuestión: Gobernadores y políticas de seguridad en cuatro provincias argentinas", Aposta Digital Nº 63 (2014), ISSN 16967348.

CRUZ CASTRO, Fernando, "La investigación y persecución de la corrupción. Observaciones fundamentales sobre el rol del Ministerio Público en los sistemas penales latinoamericanos", Pena y Estado $\mathrm{N}^{\circ} 1$ (1995), Buenos Aires: Editores del Puerto, pp. 81-88.

DUCE, Mauricio, El ministerio público fiscal en la reforma procesal penal en América latina: visión general acerca del estado de los cambios, Chile: CEJA, 2005.

GARGARELLA, Roberto, "Too far removed from the people. Access to Justice for the Poor: The Case of Latin America", 2002. Disponible en http://www.undp.org/oslocentre/PAR_Bergen_2002/latin-america.pdf

MARCHISIO, Adrián, "Principio de Oportunidad, sinceramiento del sistema y desafíos para el Ministerio Público Fiscal”, Revista del Ministerio Público Fiscal, Núm. 12 (2003), Argentina.

MENDAÑA, Ricardo, "El Ministerio Público y la dirección de la investigación criminal”, Cuadernos de derecho penal 2 (2005), Asociación de pensamiento penal, Argentina.

MENDEZ, Juan, O`DONNELL, Guillermo y PINHEIRO, Paulo (Comps.), La (in)efectividad de la ley y la exclusión en América Latina, Argentina: Paidós, 2002.

RICO, José María, Justicia penal y transición democrática en América Latina, México: Siglo XXI Editores, 1997.

RICO, José María, y CHINCHILLA, Laura, Seguridad ciudadana en América Latina, México: Siglo XXI Editores, 2002.

SADEK, Maria Tereza y BATISTA CAVALCANTI, Rosângela, "The New Brazilian Public Prosecution: An Agent of Accountability", en: MAINWARING, Scott y WELNA, Christopher (Eds.), Democratic Accountability in Latin America, Oxford: Oxford University Press, 2003. 